\title{
Research on the Reliability and Validity of Social Network Scale Based self- Reporting Method
}

\author{
Liang-qiong $\mathrm{Li}^{1, \mathrm{a}^{*}}$, Yu Zheng ${ }^{2, \mathrm{~b}}$
}

\section{School of Public Administration and Law, Liaoning Technical University, Fuxin, Liaoning, PR,china, 123000}

2.Agricultural Science and Technology Achievements Transformation Center of Fuxin, Fuxin, Liaoning, PR, china, 123000

*25563795@qq.com, b2418114845@qq.com

Keywords: Reliability.Self-report method.Social networks. Validity

Abstract. This paper uses the software Spss to analyze the reliability and validity of social network scale based self- reporting method, the results have a certain reference value, the initial Cronbach's $\alpha$ coefficient is relatively high, but it has the possibility of improving; the structure of analysis results of table 6 and original design's structure is different, the structure dimension should reduce from 4 dimensions to 3 dimensions. That provides a guarantee for the further implementation of the social network survey.

\section{Introduction}

Social networks is a structure made by a group of actors, in this structure, actors connect each other through a series of relationships ${ }^{[1]}$. John A.Barnes (1954) is considered to be the first to use "social network" terminology scholar. He is an anthropologist, studied the relationship between residents on an island in Norway. Because of the social network structure affects the individual (micro) level analysis and system (macro) level analysis, so it is thought to explain the relationship between structure changes and its results. Concepts and methods of social network have been extended to many disciplines from anthropology and sociology, and are applied to many mainstream theories and research issues.

According to Rogers and Cartano, Tong Bao's (2014) ${ }^{[2-3]}$ understanding and definition of self-report method (using questionnaires to ask consumers if they are opinion leaders and to what extent are the opinion leaders), this paper will define self-report as using a questionnaire to ask respondents about their social network structure and degree. Individual Center social network data obtained self-reported method contains more subjective, but it can collect social network data quickly and lowly, and many studies have shown that self-reported method are valid ${ }^{[4]}$.The most important thing is the self-reported method can protect the privacy of personal network relationships.

Currently, many studies used self-report scale to evaluate the individual social network status. The content and design quality of index system of social network scale impact the evaluation of social network of individuals. If there is no reasonable scientific index system, they will not get a reliable and objective evaluation of individual social networks. This paper will use statistical software spss17 to conduct reliability and validity analysis for the self-report scale of social network.

\section{Data source}

The study of the article is "social network scale based self- reporting method ".The questionnaire was designed mainly with reference to the literature (Jing-bo Shao et al., 2014) ${ }^{[5]}$, the specific content is shown in Table 1: The network boundary is defined as a professional university, the relationship's content is the exchanges and contacts among students. 
Tab.1 social network scale based self- reporting method

\begin{tabular}{|c|c|c|c|c|c|c|}
\hline \multirow{3}{*}{$\begin{array}{l}\text { Network } \\
\text { density }\end{array}$} & $\begin{array}{l}\text { ND1: I am familiar with other classmates in my } \\
\text { major }\end{array}$ & 1 & 2 & 3 & 4 & 5 \\
\hline & $\begin{array}{l}\text { ND2: Classmates in my major are familiar with } \\
\text { me }\end{array}$ & 1 & 2 & 3 & 4 & 5 \\
\hline & $\begin{array}{l}\text { ND3: I often communicate with other } \\
\text { classmates in my major }\end{array}$ & 1 & 2 & 3 & 4 & 5 \\
\hline \multirow{3}{*}{$\begin{array}{l}\text { Network } \\
\text { centrality }\end{array}$} & $\begin{array}{l}\text { NC1: I can acquire information conveniently } \\
\text { from other classmates in my major }\end{array}$ & 1 & 2 & 3 & 4 & 5 \\
\hline & $\begin{array}{l}\text { NC2: I am in the dominant position of my } \\
\text { major }\end{array}$ & 1 & 2 & 3 & 4 & 5 \\
\hline & $\begin{array}{l}\text { NC3: Most of classmates around me and I } \\
\text { maintain direct contact }\end{array}$ & 1 & 2 & 3 & 4 & 5 \\
\hline \multirow{4}{*}{$\begin{array}{l}\text { Network } \\
\text { condensed } \\
\text { subgroup }\end{array}$} & $\begin{array}{l}\text { NCS1: Here are many benefits for my } \\
\text { relationship with classmates in my subgroup }\end{array}$ & 1 & 2 & 3 & 4 & 5 \\
\hline & $\begin{array}{l}\text { NCS2: Information are transferred more and } \\
\text { faster in my subgroup }\end{array}$ & 1 & 2 & 3 & 4 & 5 \\
\hline & $\begin{array}{l}\text { NCS3: Communication in my subgroup is } \\
\text { more frequently than with members outside my } \\
\text { subgroup }\end{array}$ & 1 & 2 & 3 & 4 & 5 \\
\hline & $\begin{array}{l}\text { NCS4: Relationship in my subgroup is more } \\
\text { close than with members outside my subgroup }\end{array}$ & 1 & 2 & 3 & 4 & 5 \\
\hline \multirow[t]{2}{*}{$\begin{array}{l}\text { Network } \\
\text { scale }\end{array}$} & $\begin{array}{l}\text { NS1: My social network of major has many } \\
\text { members }\end{array}$ & 1 & 2 & 3 & 4 & 5 \\
\hline & $\begin{array}{l}\text { NS2: I maintain important touch with many } \\
\text { classmates }\end{array}$ & 1 & 2 & 3 & 4 & 5 \\
\hline
\end{tabular}

This research issues 50 questionnaires, and recovers 44 . The recycled 44 questionnaires are checked and coded, excluding a part of invalid questionnaires, 43 valid questionnaires can get, of which is 10 boys and 33 girls.

\section{Reliability analysis}

Reliability refers to the degree of consistency of the results by the same method on the same object when repeating measurements. In other words, Reliability is in term of measuring the degree of stability and consistency. Reliability analysis often uses Cronbach's $\alpha$ coefficient, split-half reliability method, $\theta$ coefficient and $\Omega$ coefficient [a].

In software spss17, the path to measure the reliability is "analysis- measure- reliability". The Cronbach's $\alpha$ coefficient is the most common reliability coefficient, and this paper use it, and the table 2 gives the following results:

Tab. 2 reliability statistic

\begin{tabular}{|r|l|l|}
\hline Cronbach's Alpha & Standard Cronbach's Alpha & item \\
\hline 0.822 & 0.816 & 12 \\
\hline
\end{tabular}

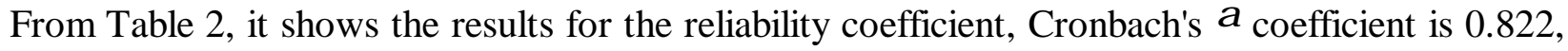
based on standard items Cronbach's $\alpha$ coefficient is 0.816 , such reliability coefficient is higher, indicating that the scale has high internal consistency. In Table 3, the sixth column indicates that if you remove the index, Cronbach's $\alpha$ coefficient changes. Seen from the sixth column, if the index is deleted, most indicators of reliability coefficient will decrease. But if NC2, NCS3 and NCS4 are deleted, the reliability coefficient index will rise. When deleting NCS3, NCS4, NC2, the reliability coefficient is improved, Cronbach's $\alpha$ coefficient is 0.844 , based on standardized Cronbach's $\alpha$ coefficient is 0.845 , 
the internal consistency of the scale is further enhanced. After that, the item total statistic is shown at Table 4.Form the sixth column of Table 4, it shows that if the index is deleted, the reliability coefficients will reduce, which means that the indicators distinguish well.

Tab. 3 item total statistic

\begin{tabular}{|l|l|l|l|l|l|}
\hline & $\begin{array}{l}\text { Deleted } \\
\text { scale } \\
\text { average }\end{array}$ & $\begin{array}{l}\text { Deleted scale } \\
\text { variance }\end{array}$ & $\begin{array}{l}\text { Item total } \\
\text { statistic } \\
\text { correlation }\end{array}$ & $\begin{array}{l}\text { square of } \\
\text { the } \\
\text { correlation }\end{array}$ & $\begin{array}{l}\text { Deleted scale } \\
\text { Cronbach's Alpha }\end{array}$ \\
\hline ND1 & 36 & 30.429 & 0.545 & 0.55 & 0.802 \\
\hline ND2 & 36.2791 & 30.92 & 0.528 & 0.65 & 0.804 \\
\hline ND3 & 36.2326 & 31.564 & 0.502 & 0.593 & 0.806 \\
\hline NC1 & 36.3023 & 30.406 & 0.514 & 0.429 & 0.805 \\
\hline NC2 & 37.1163 & 33.058 & 0.303 & 0.449 & 0.822 \\
\hline NC3 & 36.3721 & 32.001 & 0.47 & 0.526 & 0.809 \\
\hline NCS1 35.6744 & 30.987 & 0.544 & 0.574 & 0.803 \\
\hline NCS2 35.6512 & 29.994 & 0.518 & 0.639 & 0.805 \\
\hline NCS3 35.2093 & 35.217 & 0.132 & 0.593 & 0.831 \\
\hline NCS4 35.2326 33.849 & 0.243 & 0.3 & 0.826 \\
\hline NS1 & 36.2093 & 28.027 & 0.708 & 0.682 & 0.785 \\
\hline NS2 & 36.3023 & 30.597 & 0.657 & 0.629 & 0.795 \\
\hline
\end{tabular}

Tab.4 improved item total statistic

\begin{tabular}{|l|l|l|l|l|l|}
\hline & $\begin{array}{l}\text { Deleted } \\
\text { scale } \\
\text { average }\end{array}$ & $\begin{array}{l}\text { Deleted } \\
\text { scale } \\
\text { variance }\end{array}$ & $\begin{array}{l}\text { Item total } \\
\text { statistic } \\
\text { correlation }\end{array}$ & $\begin{array}{l}\text { square of the } \\
\text { correlation }\end{array}$ & $\begin{array}{l}\text { Deleted scale } \\
\text { Cronbach's Alpha }\end{array}$ \\
\hline ND1 & 25.5814 & 22.916 & 0.573 & 0.518 & 0.826 \\
\hline ND2 & 25.8605 & 23.837 & 0.494 & 0.52 & 0.834 \\
\hline ND3 & 25.814 & 23.822 & 0.546 & 0.543 & 0.829 \\
\hline NC1 & 25.8837 & 23.296 & 0.492 & 0.356 & 0.835 \\
\hline NC3 & 25.9535 & 24.426 & 0.484 & 0.519 & 0.835 \\
\hline NCS1 & 25.2558 & 23.433 & 0.572 & 0.485 & 0.826 \\
\hline NCS2 & 25.2326 & 23.04 & 0.484 & 0.427 & 0.837 \\
\hline NS1 & 25.7907 & 20.646 & 0.759 & 0.658 & 0.803 \\
\hline NS2 & 25.8837 & 23.391 & 0.646 & 0.566 & 0.82 \\
\hline
\end{tabular}

\section{Validity analysis}

Validity includes three types: construct validity, content validity and criterion validity. Construct validity refers to the degree between the structure and the measured values which reflected in measurement results. Content validity refers to whether the designed questions are the representative to measure the content or theme. According to self-reported method social network questionnaire, this paper will analyze the construct validity.

To measure the construct validity, this paper will use factor analysis, to extract some of the common factors from all indicators of questionnaire scale. These common factor, which represents the basic structure of the scale, examining whether the statistical structure and the design structure of the questionnaire are consistent, judging validity according to the degree of consistency. The path in spss17 to measure the validity is "analysis- dimension reduction- factor analysis", choosing Principal Component Analysis. To process the sample which has deleted NCS3, NCS4 and NC2 index, the results are as follows: 
$\mathrm{KMO}$ and Bartlett's value is 0.773 , indicating that it is suitable for factor analysis. Explained total variance shows that the cumulative contribution factor and the factor choice number. The cumulative contribution rate reflects the cumulative effectiveness of the scale .The cumulative contribution

Tab.5 Ingredient matrix

\begin{tabular}{|l|r|r|r|}
\hline & 1 & 2 & 3 \\
\hline NCS2 & 0.829 & 0.01 & 0.114 \\
\hline NS1 & 0.738 & 0.381 & 0.287 \\
\hline NCS1 & 0.713 & 0.379 & -0.01 \\
\hline NS2 & 0.708 & 0.069 & 0.497 \\
\hline ND2 & -0.031 & 0.84 & 0.294 \\
\hline ND1 & 0.214 & 0.774 & 0.187 \\
\hline NC1 & 0.346 & 0.67 & -0.024 \\
\hline NC3 & 0.177 & 0.089 & 0.882 \\
\hline ND3 & 0.138 & 0.274 & 0.825 \\
\hline
\end{tabular}

rate of the first three factors reach at $72.36 \%$, which can meet the requirements of the cumulative contribution rate, so they can choose the three factors(see tab.5). As can be seen from table 6, indicators NS1, NS2, NCS2 and NCS1 are associated with the first factor, so they can form a module, combining with the contents of each index, this module reflects the network circle conditions. The indexes of ND1, ND2 and NC1 are associated with the second factor, so they can form a module, the module reflects network density conditions. The indicators of NC3 and ND3 are associated with the third factor, so they can form a module, the module reflects the network centrality conditions. Comparing the structure of analysis results of table 6 and original design's structure, this paper suggests that, the structure dimension should reduce from 4 dimensions to 3 dimensions.

\section{Conclusion}

The reliability analysis of social network scale based self- reporting method shows: the initial Cronbach's $\alpha$ coefficient is relatively high, but it has the possibility of improving. When deleting the NCS3, NCS4 , NC2 item ,the Cronbach's $\alpha$ coefficient reached to 0.845 . Using factor analysis to analyze validity shows that the structure of analysis results of table 6 and original design's structure is different, the structure dimension should reduce from 4 dimensions to 3 dimensions.ND1, ND2 and NC1 reflect the network density dimension, S1, NS2, NCS1 and NCS2 reflect the network circle dimensions, NC3 and ND3 reflect the network centrality dimension.

\section{References}

[1]David Knoke, songyang ( translator) .Social Network Analysis . 2nd Edition[M]. Gezhi publication. 2012.10

[2]E.M.Rogers,D.G.Cartano,Methods of measuring opinion leadership[J].Public Opinion Quarterly .1962,435-441

[3]Tong Bao, Tung-lung Steven Chang. Finding disseminators via electronic word of mouth message for effective marketing communications. Decision Support Systems[J].2014,21-29

[4]Marsden,P.V.Core discussion networks of Americans.American Sociological Review,1987,122-131

[5]Jing-bo Shao, Jun-hui Zhang, Bei-bei Guo. Research on the influencing factors of customer referral behavior based on social network-Application in thecatering industry[J]. Journal of High Technology Management Research . 2014, 163-17 